\title{
Ulcerated Necrobiosis Lipoidica
}

\section{Necrobiose Lipoidica Ulcerada}

Rita PIMENTA $\rrbracket^{1}$, Ângela RODA 1 , João Pedro FREITAS ${ }^{1,2}$

Acta Med Port 2018 Jul-Aug;31(7-8):440-440 - https://doi.org/10.20344/amp.10477

Keywords: Diabetes Mellitus; Hyperbaric Oxygenation; Leg Ulcer; Necrobiosis Lipoidica; Hyperbaric oxygen therapy, Ulcers

Palavras-chave: Diabetes Mellitus; Necrobiose Lipoídica; Oxigenação Hiperbárica; Úlcera da Perna

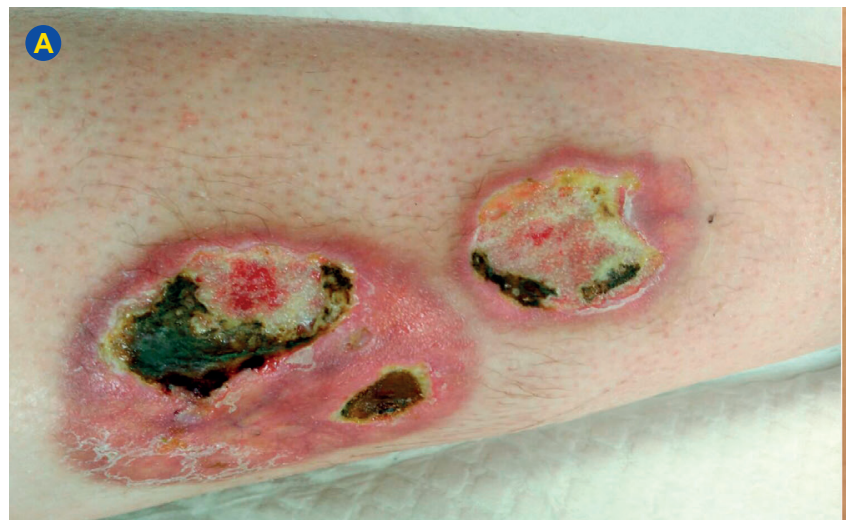

B

Figure 1 - Atrophic, yellowish-red plaques with ulcerated and necrotic center in the pretibial area (A). Wounds completely healed (B).

A 23-year-old Caucasian female, with type I diabetes mellitus, presented with a 7-month history of two painful yellowish-red plaques with ulcerated centre in the left leg (Fig. 1A). A diagnosis of ulcerated necrobiosis lipoidica (NL) was made and she was started on pentoxifylline 400 $\mathrm{mg}$ tid and tacrolimus ointment $0.1 \%$. After four months of treatment with no improvement, the patient was proposed for hyperbaric oxygen therapy (HBOT). Overall, she received a total of 30 sessions of HBOT, after which the

\section{PROTECTION OF HUMANS AND ANIMALS}

The authors declare that the procedures were followed according to the regulations established by the Clinical Research and Ethics Committee and to the Helsinki Declaration of the World Medical Association.

\section{DATA CONFIDENTIALITY}

The authors declare having followed the protocols in use at their working center regarding patients' data publication. wounds healed completely (Fig. 1B). There have been no recurrences in the 14 months following resolution.

$\mathrm{NL}$ is a rare idiopathic granulomatous disease, frequently associated with diabetes mellitus. ${ }^{1}$ The diagnosis is clinical, but a skin biopsy might be necessary in atypical lesions. ${ }^{1}$ Ulceration is the main complication and current therapeutic options are limited. Some studies demonstrated lower oxygen tension on NL lesions, suggesting that HBOT can be a valuable therapeutic option. ${ }^{2}$

\section{PATIENT CONSENT}

Obtained.

\section{CONFLICTS OF INTEREST}

All authors report no conflict of interest.

\section{FUNDING SOURCES}

This research received no specific grant from any funding agency in the public, commercial, or not-for-profit sectors.

\section{REFERENCES}

1. Reid SD, Ladizinski B, Lee K, Baibergenova A, Alavi A. Update on necrobiosis lipoidica: a review of etiology, diagnosis, and treatment options. J Am Acad Dermatol. 2013;69:783-91.

2. Sibbald C, Reid S, Alavi A. Necrobiosis lipoidica. Dermatol Clin. 2015;33:343-60.

\footnotetext{
1. Department of Dermatology. Centro Hospitalar Lisboa Norte. Lisboa. Portugal.

2. Instituto de Medicina Molecular. Faculdade de Medicina. Universidade de Lisboa. Lisboa. Portugal.

$\bowtie$ Autor correspondente: Rita Pimenta. ritapimenta@campus.ul.pt

Recebido: 04 de março de 2018 - Aceite: 30 de abril de 2018 | Copyright @ Ordem dos Médicos 2018
} 